\title{
Highly Efficient Access to 4-Chloro-2H-chromenes and 1,2-Dihydroquinolines under Mild Conditions: TMSCl-Mediated Cyclization of 2-Propynolphenols/Anilines
}

\author{
Xian-Rong Song, ${ }^{\mathrm{a}}$ Ren Li, ${ }^{\mathrm{a}}$ Haixin Ding, ${ }^{\mathrm{a}}$ Ruchun Yang, ${ }^{\mathrm{a}}$ Qiang Xiao*a and Yong-Min Liang ${ }^{b}$ \\ ${ }^{a}$ Institute of Organic Chemistry, Jiangxi Science \& Technology Normal University, Key Laboratory of Organic Chemistry, Jiangxi Province, Nanchang 330013, \\ China \\ ${ }^{b}$ State Key Laboratory of Applied Organic Chemistry, Lanzhou University, Lanzhou 730000, China.
}

\section{ARTICLE INFO}

Article history:

Received

Received in revised form

Accepted

Available online

\section{Keywords}

2-Propynolphenols/Anilines

4-Chloro-2 $\mathrm{H}$-chromenes/quinolines

TMSCl-Mediated

Cyclization

\section{ABSTRACT}

A novel and efficient TMSCl-mediated cyclization reaction of easily prepared 2propynolphenols/anilines is developed to give 4-chloro- $2 H$-chromenes and 1,2-Dihydroquinolines in good to efficient yields. It is noted that $\mathrm{TMSCl}$ acts not only as a promoter in this reaction, and also as the chloro source. Both tertiary and secondary propargylic alcohols with diverse functional groups were tolerated under the mild conditions. Moreover, this method can be enlarged to gram scale (yield up to $90 \%$ ).

\section{Introduction}

$2 \mathrm{H}$-chromene is a considerably significant flavonoid skeletal structure, which widely distributes in a variety of natural products and pharmaceutically active molecules. ${ }^{[1-3]}$ Meanwhile, in view of the potential bioactivity and pharmaceutical activities of such compounds, as well as the crucial position in organic synthetic chemistry, the development of atom- and step-economical approaches for the synthesis of benzopyran structures has attracted considerable attentions. The general approaches for the synthesis of functionalized $2 \mathrm{H}$-chromenes include the modification of pre-constructed of chromonone nucleus, ${ }^{[4]}$ and the cyclization of substituted phenolic propargyl ether compounds. ${ }^{[5]}$ Not long ago, Kumar and Su group reported a mild synthesis of 4-chloro- $2 \mathrm{H}$-chromenes from the Vilsmeier-type reaction of 2'-hydroxychalcones. ${ }^{[6]}$ Despite these pioneering methodologies for the synthesis of $2 \mathrm{H}$ chromenes, some of them suffered one or more shortcomings, such as tedious procedures, harsh conditions, limited substrates, and the unsatisfactory yields. So, it is still desirable to develop an efficient and straightforward method for the synthesis of functionalized $2 \mathrm{H}$-chromenes in mild conditions with broad substrates scope.

Owing to the potential intrinsic reactivity of alkynols, the tandem reaction of alkynols has recently received considerable attention and has become powerful tool for the construction of various carbo- and heterocyclic compounds. ${ }^{[7]}$ Recently, our group developed a tandem process to synthesize heterocyclic building blocks by using 2-propynolphenols as the starting materials. $^{[8]}$ To the best of our knowledge, the direct transformation of 2-propynolphenols to 4-chloro- $2 \mathrm{H}$-chromenes has been not disclosed yet. As shown in scheme 1, 4-chloro- $2 \mathrm{H}$ chromenes have been extensively used as valuable intermediates for the construction of various $O$-heterocyclic compounds with potential bioactivity. ${ }^{[9-12]}$ Herein, we describe an efficient and novel approach to access 4-chloro- $2 H$-chromenes or 1,2dihydroquinolines under mild reaction conditions (Scheme 1). Compared to the traditional strategies, our developed methods could be conveniently operated, which may open up a new potential application for these systems in industrial production. It is noted that $\mathrm{TMSCl}$ acts not only as a promoter in this reaction, and also as the chloro source.

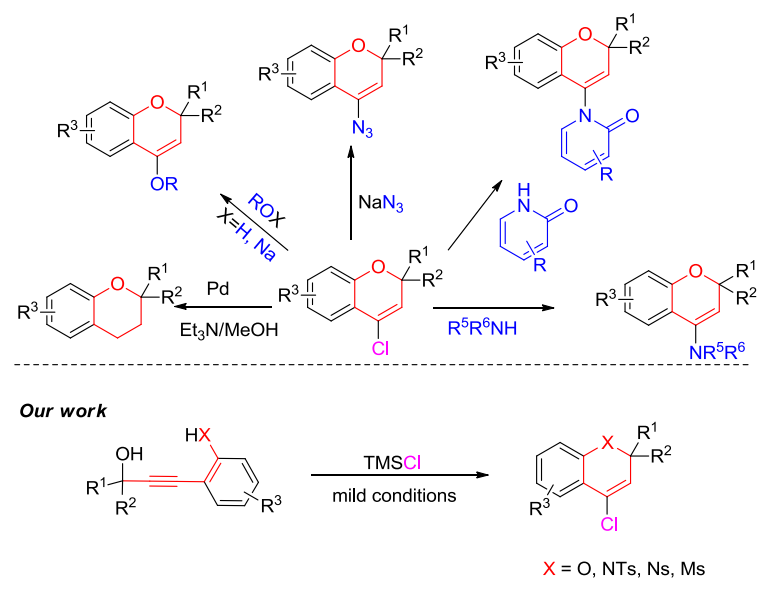

Scheme 1 Various applications of 4-chloro- $2 H$-chromenes and our work 


\section{Results and Discussion}

The initial exploration for the construction of 4-chloro- $2 \mathrm{H}$ chromenes began by employing 2-propynolphenols $\mathbf{1 a}(0.2 \mathrm{mmol})$ as the model substrate with $\mathrm{TMSCl}$ (1.5 equiv) in $\mathrm{CH}_{3} \mathrm{NO}_{2}$ at $50{ }^{\circ} \mathrm{C}$ for $1.0 \mathrm{~h}$ (Table 1 , entry 1 ). To our delight, the desired product, 4-chloro-2,2-diphenyl-2H-chromene (2a), was isolated in $87 \%$. Subsequently, various representative solvents were screened. And MeCN proved to be the most efficient one, which increased the yield of $\mathbf{2 a}$ to $95 \%$ (Table 1 , entries 2-7). When the temperature was increased to 80 ${ }^{\circ} \mathrm{C}, 2 \mathrm{a}$ was obtained in a lower yield (Table 1 , entry 8). We considered that a higher temperature was advantageous to the side reaction. $79 \%$ yield of $\mathbf{2 a}$ was obtained at room temperature for $4.0 \mathrm{~h}$ due to the relatively lower reactivity, as expected (Table 1, entry 9). Furthermore, other adjustments indicated that the most appropriate amount of TMSCl was 1.5 equiv (Table 1 , entries 10-11). In addition, no better yields were obtained, when conc. $\mathrm{HCl}(12 \mathrm{~mol} / \mathrm{L})$ was applied instead of TMSCl in this reaction (Table 1, entry 12). Ultimately, the optimal reaction conditions for generating $\mathbf{2 a}$ were determined to be the use of TMSCl (1.5 equiv) in $\mathrm{MeCN}(2.0 \mathrm{~mL})$ at $50{ }^{\circ} \mathrm{C}$ for $1.0 \mathrm{~h}$.

Table 1 Optimization of the reaction conditions ${ }^{a}$

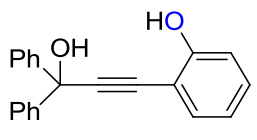

$1 \mathrm{a}$

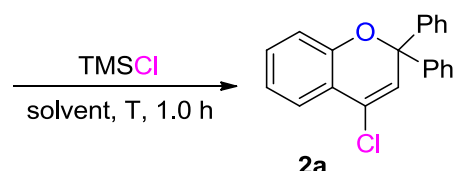

$2 a$

\begin{tabular}{clrcl}
\hline Entry & Solvent & $\begin{array}{r}\text { TMSCl } \\
\text { (equiv) }\end{array}$ & $T\left[{ }^{\circ} \mathrm{C}\right]$ & Yield \\
\hline 1 & $\mathrm{MeNO}_{2}$ & 1.5 & 50 & 87 \\
2 & $\mathrm{DCE}$ & 1.5 & 50 & 91 \\
3 & $\mathrm{MeCN}$ & 1.5 & 50 & 95 \\
4 & $\mathrm{CH}_{2} \mathrm{Cl}_{2}$ & 1.5 & 50 & 88 \\
5 & $\mathrm{THF}$ & 1.5 & 50 & 89 \\
6 & $\mathrm{HOAc}$ & 1.5 & 50 & 91 \\
7 & $1,4-\mathrm{dioxane}$ & 1.5 & 50 & 90 \\
8 & $\mathrm{MeCN}$ & 1.5 & 80 & 90 \\
$9^{b}$ & $\mathrm{MeCN}$ & 1.5 & $\mathrm{rt}$ & 79 \\
10 & $\mathrm{MeCN}$ & 2.0 & 50 & 96 \\
11 & $\mathrm{MeCN}$ & 1.2 & 50 & 90 \\
$12^{c}$ & $\mathrm{MeCN}$ & 1.5 & 50 & 86
\end{tabular}

${ }^{\mathrm{a}}$ Unless otherwise noted, all reactions were performed with $0.2 \mathrm{mmol}$ of $\mathbf{1 a}$ with TMSCl, in solvent $(2.0 \mathrm{~mL})$ at $50{ }^{\circ} \mathrm{C} .{ }^{\mathrm{b}} 4.0 \mathrm{~h} .{ }^{\mathrm{c}} \mathrm{HCl}$ was used instead of TMSCl.

With the optimized reaction conditions in hand, a variety of substituted 2-propynolphenols were prepared to investigate the scope of this tandem reaction. The corresponding 4-chloro- $2 \mathrm{H}$-chromene products (2a-2o) were obtained in good to excellent yields (up to 97\%) under the optimal reaction conditions (Table 2). The structure of 2n was also confirmed by an X-ray diffraction (see the Supporting Information). Firstly, various substituted tertiary propargylic alcohols $\mathbf{1}$ were treated with TMSCl to explore the substituents effects. In general, both electron-donating $(\mathrm{Me}, \mathrm{OMe})$ and -withdrawing $(\mathrm{F}, \mathrm{Cl})$ substituents on either of the two aryl groups could be tolerated and afforded the desired products in good to excellent yields $(\mathbf{2 a}-\mathbf{2} \mathbf{j})$. Moreover, the steric effect of substituents exerted a clear influence on this transformation; the substituents on the ortho-position of aryl groups gave slightly lower yields (2g). When the substrates with two different aryl groups $\left(\mathrm{R}^{1} \neq \mathrm{R}^{2}\right)$ were employed under optimal reaction conditions, the corresponding products were obtained in good to excellent yields $(\mathbf{2} \mathbf{g}-\mathbf{2 j})$. Furthermore, substrates with diverse substituents ( $\mathrm{Me}, \mathrm{Cl}$ and $\mathrm{Br}$ ) as the $\mathrm{R}^{3}$ group could also readily participate in this tandem reaction to generate the desired products in excellent yields $(\mathbf{2 l}-\mathbf{2 n})$. Especially, the

Table 2 Transformation of tertiary propargylic alcohols to 4-chloro- $2 \mathrm{H}$-chromenes ${ }^{\mathrm{a}}$
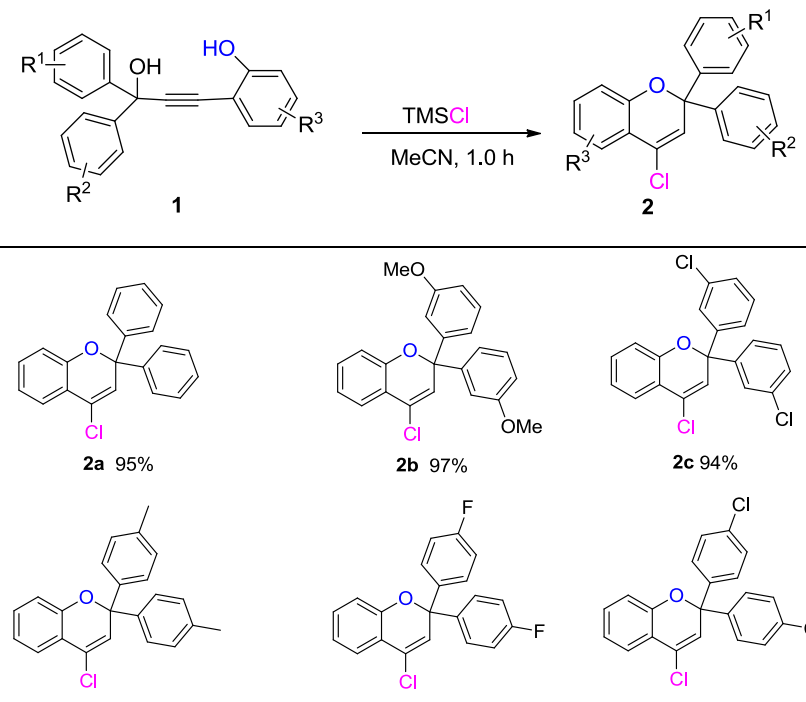

2b $97 \%$

2c $94 \%$
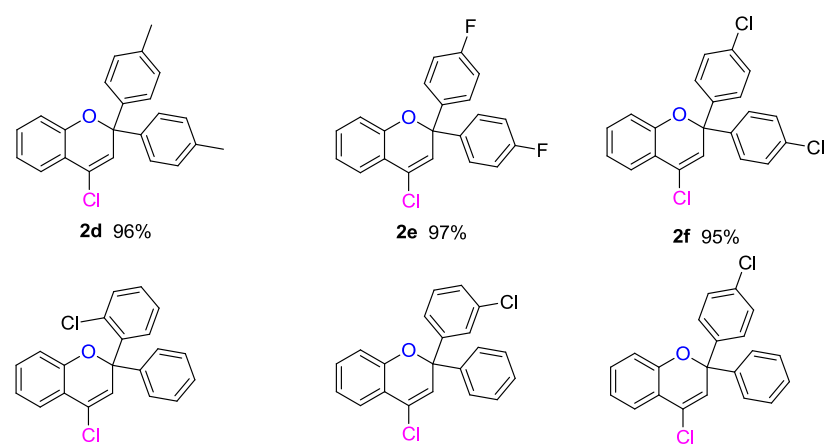

2e $97 \%$

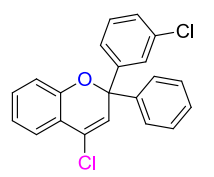

2h $95 \%$
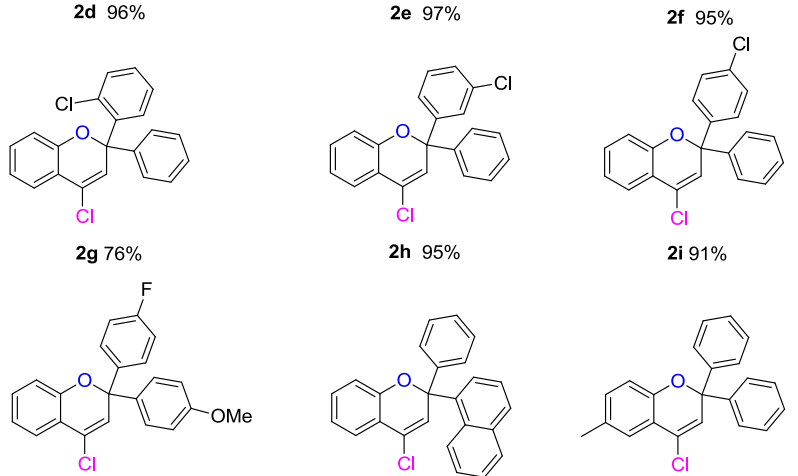

2j $92 \%$
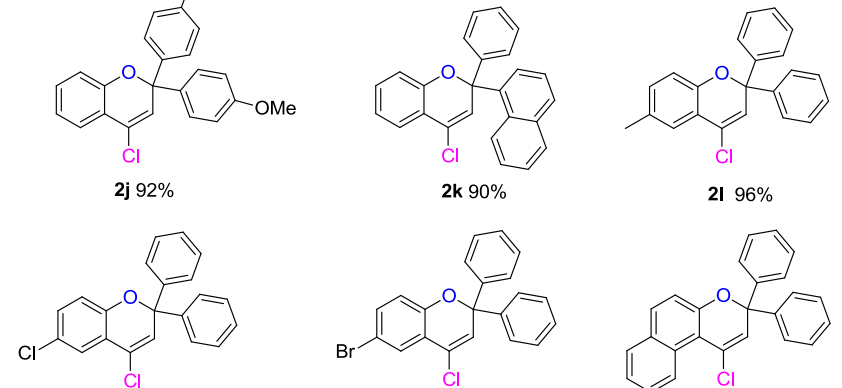

2 m $93 \%$

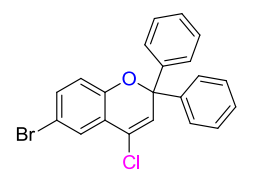

2n $90 \%$

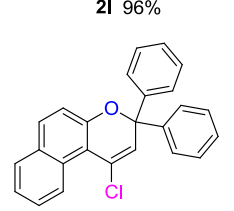

20 $94 \%$

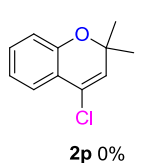

${ }^{\mathrm{a}}$ Unless otherwise noted, all reactions were performed with $0.2 \mathrm{mmol}$ of $\mathbf{1}, 1.5$ equiv of $\mathrm{TMSCl}$ in $\mathrm{CH}_{3} \mathrm{CN}(2.0 \mathrm{~mL})$ at $50{ }^{\circ} \mathrm{C}$.

reaction proceeded smoothly for the substrates with a multiple-ring group (naphthyl group, $\mathbf{1 k}$ and 1o). 
Unfortunately, no desired product was obtained when alkylsubstituted propargylic alcohol $1 \mathbf{p}$ was employed in this reaction.

Encouraged by the above results, the reactions of secondary propynols were also examined under the optimized reaction conditions (Table 3). Some representative substrates $\mathbf{3 a}-\mathbf{3 h}$ smoothly transformed into the corresponding mono-phenyl substituted 4-chloro- $2 \mathrm{H}$ chromenes in good to excellent yields $(\mathbf{4 a}-\mathbf{4 h})$. And the electronic properties of the substituent $\left(\mathrm{R}^{1}\right)$ exerted a clear influence on this transformation. Substrates with electronrich moieties on $\mathrm{R}^{1}$ showed better results than those with electron-withdrawing ones in this transformation (3e vs $\mathbf{3 f}$ ).

Table 3 Transformation of secondary propargylic alcohols into 4-chloro-2H-chromenes ${ }^{\mathrm{a}}$

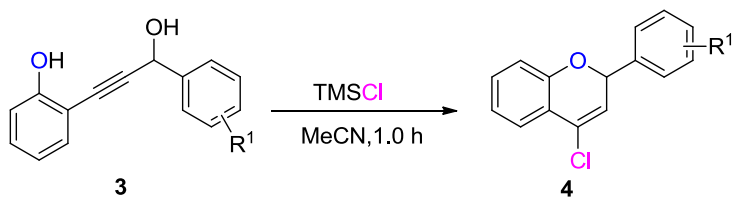

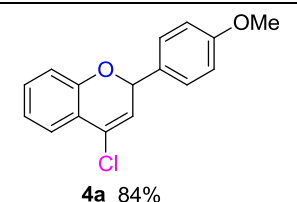

4a $84 \%$<smiles>ClC1=CC(c2ccc(Cl)cc2)Oc2ccccc21</smiles>

4d $94 \%$

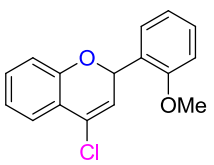

$4 \mathrm{~g} 88 \%$

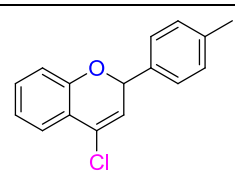

4b $87 \%$

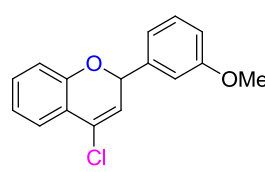

4e $90 \%$

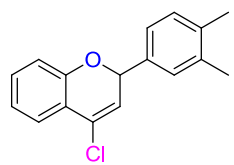

4h $96 \%$
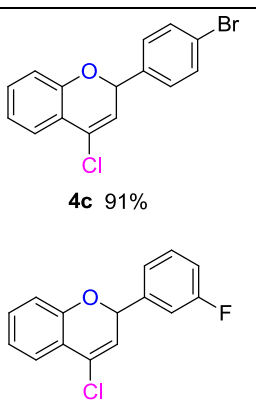

4f $74 \%$
${ }^{a}$ Unless otherwise noted, all reactions were performed with $0.2 \mathrm{mmol}$ of 3,1.5 equiv of TMSCl in $\mathrm{CH}_{3} \mathrm{CN}(2.0 \mathrm{~mL})$ at $50{ }^{\circ} \mathrm{C}$.

Table 4 Transformation of 2-propynolanilines into 4-chloro$2 H$ - quinolines ${ }^{\text {a }}$

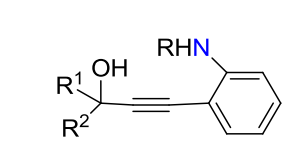

5

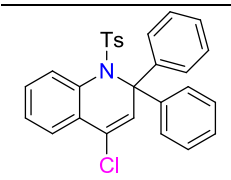

6a $91 \%$

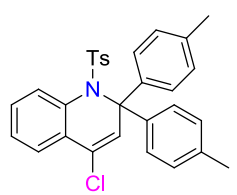

6d $94 \%$
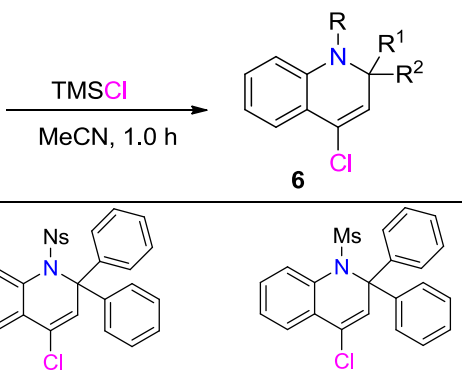

6c $96 \%$

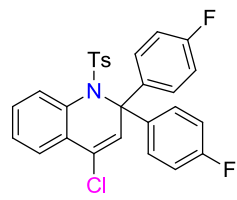

6e $88 \%$

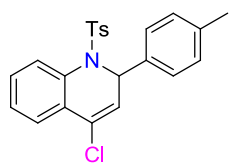

6f $87 \%$
${ }^{a}$ Unless otherwise noted, all reactions were performed with $0.2 \mathrm{mmol}$ of $\mathbf{5}, 1.5$ equiv of $\mathrm{TMSCl}$ in $\mathrm{CH}_{3} \mathrm{CN}(2.0 \mathrm{~mL})$ at $50{ }^{\circ} \mathrm{C}$. $\mathrm{Ns}=p$-Nitrobenzenesulfonyl. Ms = Methanesulfonyl.
In addition, some representative 2-propynolanilines 5a5f were also investigated under the optimal conditions, and the corresponding products 4-chloro- $\mathrm{H}$-quinolines were obtained in good to excellent yields (Table 4). 1,2Dihydroquinolines are important organic synthetic intermediates for pharmaceuticals, antimicrobials, and biologically active compounds. ${ }^{[13]}$

Noticeably, an obvious advantage of our developed reaction system is that this reaction could be scaled-up to gram quantities. When substrate 2-propynolphenol 1a (1.0 g) was performed under the optimal reaction conditions, the corresponding product 2a was obtained in a high yield to $90 \%$, which might provide a potential application in organic synthesis industrial production (Scheme 2).

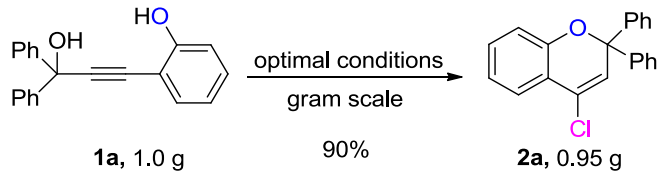

Scheme 2 Scale-up experiment

Moreover, the synthetic application of the 4-chloro- $2 \mathrm{H}$ chromene products was demonstrated by an array of palladium-catalyzed cross-coupling reactions (Scheme 3). ${ }^{[14]}$ Suzuki-Miyaura coupling of $\mathbf{2} \mathbf{b}$ with arylboronic acid proceeded by using $\mathbf{L 1}$ as the ligand to yield $\mathbf{7}$ in good yields (Scheme 3a). The products $\mathbf{2 b}$ also underwent Sonogashira coupling with 4-methoxyphenylacetylene by using $\mathbf{L 2}$ as the ligand to provide $\mathbf{8}$ in moderate yields (Scheme 3b).

a)
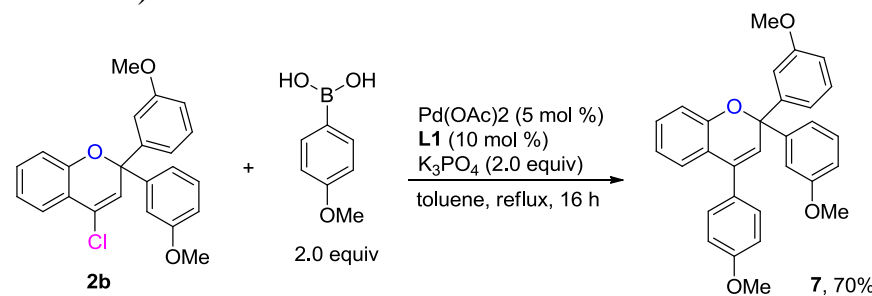

b)
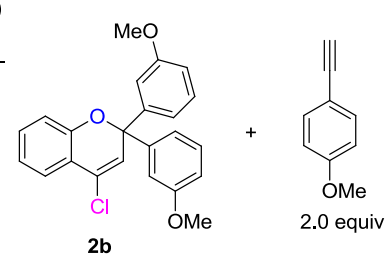

$\mathrm{Pd}(\mathrm{OAc}) 2(5 \mathrm{~mol} \%)$ L2 $(10 \mathrm{~mol} \%)$ $\mathrm{Cul}(10 \mathrm{~mol} \%)$ $i \mathrm{Pr}_{2} \mathrm{NH}$, reflux, $16 \mathrm{~h}$

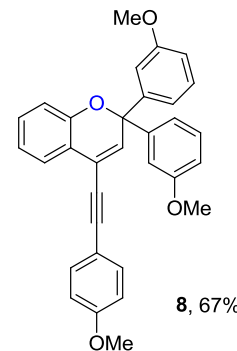

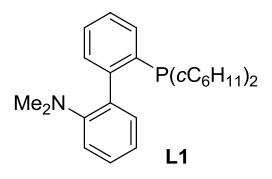

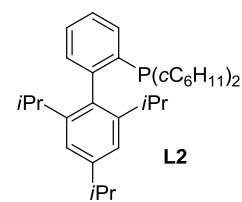

Scheme 3 Synthetic application

On the basis of the above detailed investigation and previous reports, ${ }^{[15]}$ a plausible mechanism of this transformation is shown in Scheme 4. Firstly, propargylic alcohol $\mathbf{1}$ is converted to the propargylic cation $\mathbf{A}$ in the presence of $\mathrm{TMSCl}$, which would then undergo a mesomerism to produce the allenic cation $\mathbf{B}$. Then the allenic substitution occurs by the attack of the chloro anion, resulting in intermediate $\mathbf{C}$. Intermediate $\mathbf{C}$ could then be protonated to give intermediate $\mathbf{D}$, which is attacked by the 
phenolic hydroxy group to produce product 4-chloro- $2 \mathrm{H}$ chromene 2.

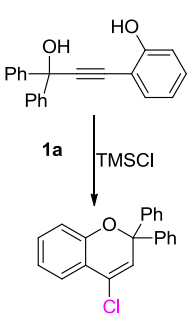

2a

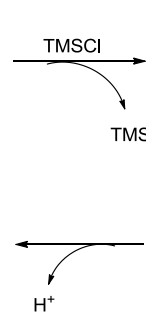

$\mathrm{H}^{+}$
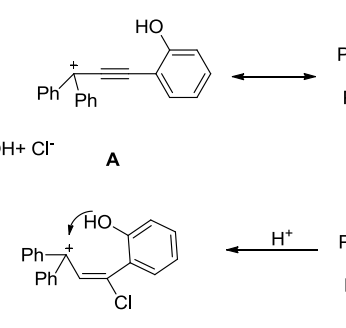

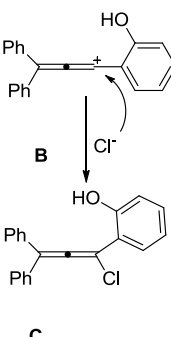

C
Scheme 4 Proposed mechanism.

In conclusion, we have developed a novel and highly efficient method for the construction of 4-chloro- $2 \mathrm{H}$ chromenes and -1,2-Dihydroquinolines via a TMSClmediated cyclization reaction of propargyl alcohols. This reaction performed smoothly with a $\mathrm{C}-\mathrm{Cl}$ bond and a $\mathrm{C}-\mathrm{O} / \mathrm{N}$ bond constructed concurrently under mild conditions in very high yields (up to 97\%). It is noted that TMSCl acted as not only a promoter, and also the chloro source in this reaction. In addition, this reaction system could be enlarged to gram scale in an excellent yield to $90 \%$ under very mild conditions, which might provide a potential application in the organic synthesis for industrial production.

\section{Acknowledgments}

We acknowledge the Jiangxi Science \& Technology Normal University and the Education Department of Jiangxi Province (GJJ150806) for financial support. We also thank the National Science Foundation (NSF21462019) for financial support.

\section{References and notes}

1. Cassidy, J. M.; Evans, M. S.; Hadley, A. H.; Haladij P. E.; Stemp, G. J. Med. Chem. 1992, 35, 1623.

2. (a) Bauer, D. J.; Selway, T. J. W.; Batchelor, J. F.; Tisdale, M.; Caldwell, I. C.; Young, D. A. B. Nature 1981, 292, 369; (b) Paul, N. D.; Mandal, S.; Otte, M.; Cui, X.; Zhang, X. P.; de Bruin, B. J. Am. Chem. Soc. 2013, 135, 1090; (c) Trenor, S. R.; Shultz, A. R.; Love, B. J.; Long, T. E. Chem. Rev. 2004, 104, 3059.

3. (a) Nicolaou, K. C.; Pfefferkorn, J. A.; Roecker, A. J.; Cao, G. Q.; Barluenga, S.; Mitchell, H. J. J. Am. Chem. Soc. 2000, 122, 9939; (b) Moquist, P. N.; Kodama, T.; Schaus, S. E. Angew. Chem. Int. Ed. 2010, 49, 7096; (c) Graham, T. J. A.; Doyle, A. G. Org. Lett. 2012, 14, 1616; (d) Brieke, C.; Heckel, A. Chem. Eur. J. 2013, 19, 15726; (e) Hesse, R.; Gruner, K. K.; Kataeva, O.; Schmidt A. W.; Knöker, H.-J. Chem. Eur. J. 2013, 19, 14098; (f) Kumar, V. P.; Gruner, K. K.; Kataeva, O.; Knöker, H.-J. Angew. Chem. Int. Ed. 2013, 52, 11073; (g) Shunatona, H. P.; Fr_h, N.; Wang, Y.- M.; Rauniyar, V.; Toste, F. D. Angew. Chem. Int. Ed. 2013, 52, 7724; (h) Terada, M.; Yamanaka, T.; Toda, Y. Chem. Eur. J. 2013, 19, 13658; (i) Trost, B. M.; Bringley, D. A.; Zhang,
T.; Cramer, N. J. Am. Chem. Soc. 2013, 135, 16720; (j) Sun, S.; Bai, R.; Gu, Y. Chem. Eur. J. 2014, 20, 549; (k) Zheng, P.; SomersanKarakaya, S.; Lu, S.; Roberts, J.; Pingle, M.; Warrier, T.; Little, D.; Guo, X.; Brickner, S. J.; Nathan, C. F.; Gold, B.; Liu, G. J. Med. Chem. 2014, 57, 3755.

4. Brown, P. E.; Marcus, W. Y.; Anastasis, P. J. Chem. Soc., Perkin Trans. $1 \mathbf{1 9 8 5}, 6,1127$.

5. (a) Nevado, C.; Echavarren, A. M. Chem. Eur. J. 2005, 11, 3155; (b) Efe, C.; Lykakis, I. N.; Stratakis, M. Chem. Commun. 2011, 47, 803; (c) Mo, J.; Eom, D.; Lee, E.; Lee, P. H. Org. Lett. 2012, 14, 3684; (d) Park, J.; Kim, S.-Y.; Kim, J.-E.; Cho, C.-G. Org. Lett. 2014, 16, 178; (e) Walkinshaw, A. J.; Xu, W.; Suero, M. G.; Gaunt, M. J. J. Am. Chem. Soc. 2013, 135, 12532; (f) Li, D.-P.; Pan, X.-Q.; An, L.-T.; Zou, J.-P.; Zhang, W. J. Org. Chem. 2014, 79, 1850; (g) Murase, H.; Senda, K.; Senoo, M.; Hata, T.; Urabe, H. Chem. Eur. J. 2014, 20, 317; (h) Niu, D.; Hoye, T. R. Nat. Chem. 2014, 6, 34; (i) Pan, X.; Chen, M.; Yao. L.; Wu, J. Chem. Commun. 2014, 50, 5891.

6. (a) Kumar, K. H.; Perumal, P. T. Chem. Lett. 2005, 34, 1346; (b) Li, Z.H.; Zheng, C.; Su, W.-K. J. Heterocyclic Chem., 2008, 45, 1195.

7. (a) Zhu, Y.; Sun, L.; Lu, P.; Wang, Y. ACS Catal., 2014, 4, 1911; (b) Zhang, X.; Teo, W. T.; Sally; Chan, P. W. H. J. Org. Chem. 2010, 75, 6290; (c) Zhang, X.; Teo, W. T.; Chan, P. W. H. Org. Lett. 2009, 11, 4990; (d) Huang, W.; Shen, Q.; Wang, J.; Zhou, X. J. Org. Chem. 2008, 73, 1586; (e) Lee, K.; Lee, P. H. Org. Lett. 2008, 10, 2441; (f) Sanz, R.; Miguel, D.; Martinez, A.; Alvarez-Gutierrez, J. M.; Rodriguez, F. Org. Lett. 2007, 9, 727.

8. (a) Ye, Y.-Y.; Zhao, L.-B.; Zhao, S.-C.; Yang, F.; Liu, X.-Y.; Liang, Y.M. Chem. Asian J. 2012, 7, 2014; (b) Qiu, Y.-F.; Ye, Y.-Y.; Song, X.-R.; Zhu, X.-Y.; Yang, F.; Song, B.; Wang, J.; Hua, H.-L.; He,; Han, Y.-P.; Liu, X.-Y.; Liang, Y.-M. Chem. Eur. J. 2015, 21, 3480. (c) Qiu, Y.F.; Song, X.-R.; Li, M.; Zhu, X.-Y.; Wang, A.-Q.; Yang, F.; Han, Y.P.; Zhang, H.-R.; Jin, D.-P.; Li, Y.-X.; Liang, Y.-M. Org. Lett., 2016, 18, 1514; (d) Song, X.-R.; Qiu, Y.-F.; Song, B.; Hao, X.H.; Han, Y.-P.; Gao, P.; Liu, X.-Y.; Liang, Y.-M. J. Org. Chem., 2015, 80, 2263.

9. (a) Rimbault, C. G.; Narbel, P. M. American Patent 4,665,202, 1985; Chem. Abstr. 1985, 104, 50730; (b) Tibor, E.; Tibor, T. Synth. Commun. 1990, 20, 3219; (c) Bergmann, R.; Gericke, R. J. Med. Chem. 1990, 33, 492.

10. Venkati, M.; Krupadanam, G. L. D. Synth. Commun. 2001, 31, 2589.

11. Ishizuka, N.; Matsumura, K. I.; Sakai, K.; Fujimoto, M.; Mihara, S. I.; Yamamori, T. J. Med. Chem., 2002, 25, 2041.

12. (a) Beccalli, E. M.; Contini, A.; Trimarco, P. Tetrahedron 2005, 61, 4957; (b) Hegab, M. H.; Abdulla, M. M. Arch. Pharm. Chem. Life. Sci. 2006, 339, 41 .

13. (a) Dillard, R. D.; Pavey, D. E.; Benslay, D. N. J. Med. Chem., 1973, 16 , 251; (b) Elmore, S. W.; Coghlan, M. J.; Anderson, D. D.; Pratt, J. K.; Green, B. E.; Wang, A. X.; Staschko, M. A.; Lin, C. W.; Tyree, C. M.; Miner, J. N.; Jacobson, P. B.; Wilcox, D. M.; Lane, B. C. J. Med. Chem. 2001, 44, 4481. (c) Lesson, P. D.; Carling, T. W.; Moore, K. W.; Moseley, A. M.; Smith, G. Stevenson, T. Chan, R. Baker, A. C. Foster, S. Grimwood, J. D.; Kemp, J. A.; Marschall, G. R.; Hoogsteen, K. J. Med. Chem. 1992, 35, 1954.

14. Wada, T.; Iwasaki, M.; Kondoh, A.; Yorimitsu, H.; Hideki Yorimitsu Oshima, K. Chem. Eur. J. 2010, 16, 10671.

15. (a) Zhang, H.; Tanimoto, H.; Morimoto, T.; Nishiyama, Y.; Kakiuchi, K. Org. Lett. 2013, 15, 5222; (b) Zhu, Y.; Yin, G.; Hong, D.; Lu, P.; Wang, Y. Org. Lett. 2011, 13, 1024; (c) Zhu, Y.; Wen, S.; Yin, G.; Hong, D.; Lu, P.; Wang, Y. Org. Lett. 2011, 13, 3553. 


\section{Graphical Abstract}

To create your abstract, type over the instructions in the template box below.

Fonts or abstract dimensions should not be changed

Highly Efficient Access to 4-Chloro-2H-
chromenes and 1,2-Dihydroquinolines under
Mild Conditions: TMSCl-Mediated
Cyclization of 2-Propynolphenols/Anilines
Xian-Rong Song, ${ }^{a}$ Ren $\mathrm{Li}^{\text {a }},{ }^{\mathrm{H}} \mathrm{Haixin} \mathrm{Ding},{ }^{\mathrm{a}}$ Ruchun $\mathrm{Yang}^{\mathrm{a}}$
Qiang Xiao*a ${ }^{\mathrm{a}}$ and Yong-Min Liang

or altere 